\title{
Surgical stapling device-tissue interactions: what surgeons need to know to improve patient outcomes
}

This article was published in the following Dove Press journal:

Medical Devices: Evidence and Research

12 September 2014

Number of times this article has been viewed

\author{
Edward Chekan' \\ Richard L Whelan² \\ 'Ethicon Inc., Cincinnati, OH, USA; \\ ${ }^{2}$ St Luke's Roosevelt Hospital, \\ New York, NY, USA
}

\begin{abstract}
The introduction of both new surgical devices and reengineered existing devices leads to modifications in the way traditional tasks are carried out and allows for the development of new surgical techniques. Each new device has benefits and limitations in regards to tissue interactions that, if known, allow for optimal use. However, most surgeons are unaware of these attributes and, therefore, new device introduction creates a "knowledge gap" that is potentially dangerous. The goal of this review is to present a framework for the study of devicetissue interactions and to initiate the process of "filling in" the knowledge gap via the available literature. Surgical staplers, which are continually being developed, are the focus of this piece. The integrity of the staple line, which depends on adequate tissue compression, is the primary factor in creating a stable anastomosis. This review focuses on published studies that evaluated the creation of stable anastomoses in bariatric, thoracic, and colorectal procedures. Understanding how staplers interact with target tissues is key to improving patient outcomes. It is clear from this review that each tissue type presents unique challenges. The thickness of each tissue varies as do the intrinsic biomechanical properties that determine the ideal compressive force and prefiring compression time for each tissue type. The correct staple height will vary depending on these tissue-specific properties and the tissue pathology. These studies reinforce the universal theme that compression, staple height, tissue thickness, tissue compressibility, and tissue type must all be considered by the surgeon prior to choosing a stapler and cartridge. The surgeon's experience, therefore, is a critical factor. Educational programs need to be established to inform and update surgeons on the characteristics of each stapler. It is hoped that the framework presented in this review will facilitate this process.
\end{abstract}

Keywords: stapler, anastomosis, bariatric, colorectal, thoracic, education

\section{Introduction}

Technological advances across numerous scientific disciplines have produced many unique surgical devices and instruments that are used during surgery. Both the ongoing introduction of new devices and continuing technical improvements in existing devices are changing the way surgeons perform traditional tasks and enabling them to develop new surgical techniques with the goal of improving patient outcomes.

An unintended consequence of these rapid technological advances is the production of a collective "knowledge gap" in surgeons" understanding of how devices interact with tissue. In many cases, surgeons may not understand either the scientific/ clinical basis for the optimal use of these devices or how to optimally take advantage of unique intricacies inherent to a particular device. Consequently, surgeons may
Correspondence: Edward Chekan Ethicon Inc., 4545 Creek Road, Cincinnati, OH 45242, USA

Tel +l 5133378160

Fax + I 5133372780

Email edchekan@its.jnj.com 
often fall back on their own experience, exercise their own judgment, or rely on anecdotal evidence, which may translate into suboptimal patient outcomes, even if the devices themselves function correctly. ${ }^{1}$

The surgical stapler is an example of a device that is commonly used during surgical procedures and, at the same time, is in an almost constant state of developmental evolution. Although these devices are highly versatile and efficient, there have been well-documented incidences of staple line leaks leading to postoperative complications that often resulted from issues not attributable to ischemia. $^{2}$ Of these, technical errors can play a significant role, potentially increasing the risk of bleeding, transfusions, and unplanned proximal diversions, particularly in gastrointestinal procedures. ${ }^{1,3}$ Many surgeons are not aware of the tissue handling characteristics and limitations of new or reengineered staplers, and thus there is a knowledge gap that can impact the clinical outcome of operations. To improve surgeons' understanding of staplers and stapler-tissue interactions with the goal being to optimize the clinical outcome and fill this knowledge gap, a framework is needed within which the existing literature can be reviewed and the available data gathered and made accessible (Table 1).

The first consideration in this simple framework pertains to the specific type of device used. Surgeons must know the basic unit used by the device (eg, staple in a stapler), the desired outcome (eg, create an anastomotic staple line), and the type of device that will perform the function (eg, stapler). The second consideration is the relevant properties of the tissue that affect its interaction with the device. Finally, the biomechanical interaction between tissue and device must be considered. An example of potential research questions regarding these device-tissue interactions for staplers is shown in Table 2.
Although these questions appear to be straightforward (see Table 2), to date, there are little to no published scientific data regarding the various tissue and device interactions and thus no definitive answers to these questions. Developing a deeper foundation to solve these issues will require a collective effort to gather, collate, and organize the available data. This effort will also require widespread collaboration between physicians, scientists, and engineers from both clinical practice and the medical device industry. Ideally, a systematic research program and subsequent educational programs would help to fill the educational gap that exists for most practicing surgeons and, very importantly, in surgical training. ${ }^{4}$

The objective of this review is to emphasize the framework for the study of device-tissue interactions and to initiate the process of "filling in" this framework with data from the available literature concerning surgical staplers. Examples of studies that describe surgical stapler-tissue interaction in bariatric, colorectal, and thoracic procedures are mentioned and referenced in this paper; however, an in-depth discussion of these topics that takes into consideration all published studies is beyond the scope of this review. In addition, more detailed information regarding individual staplers and their evolution, as well as the difference between the products of different manufacturers, can be obtained from the various companies and the literature.

\section{A framework for the study of device, tissue, and their interactions Surgical stapling devices}

While the modern surgical stapler can be traced back to the work of Humer Hültl in the early 1900s, today's instruments are markedly different, largely due to the work of innovators such as von Petz and Ravitch. ${ }^{3}$ Unlike the original devices, modern staplers are most often single-use

Table I Device-tissue interactions

\begin{tabular}{|c|c|c|c|}
\hline \multirow[t]{2}{*}{ Device tissue interactions } & \multicolumn{3}{|l|}{ Device group } \\
\hline & Stapling & Energy & Access \\
\hline \multicolumn{4}{|l|}{ Device } \\
\hline Unit: "what it is" & Staple & Heat/wave/electricity & Blade tip \\
\hline Outcome: "what it does" & Staple line & Cut/coagulate/seal & Domain \\
\hline Embodiments: "what performs it" & Staplers and cutters & $\begin{array}{l}\text { Electrocautery/ } \\
\text { ultrasonic/ablation }\end{array}$ & $\begin{array}{l}\text { Trocar/hand-assisted laparoscopic surgery/Veress } \\
\text { needle/microlap/single-port access devices }\end{array}$ \\
\hline \multicolumn{4}{|l|}{ Tissue } \\
\hline Properties: "what can be affected" & Mechanical/biochemical & Biochemical/electrical & Mechanical/biochemical \\
\hline Perfusion: "what should not be affected" & Adequate/inadequate & Adequate/inadequate & Adequate/inadequate \\
\hline \multicolumn{4}{|l|}{ Interaction } \\
\hline Dynamics: "what is affected" & Compression/tension & Heat/motion mechanics & Puncture/compression/stretching \\
\hline
\end{tabular}

Note: Reproduced from Chekan E, Whelan RL, Feng AH. Device-tissue interactions: a collaborative communications system. Ann Surg Innov Res. 20I3;7(I): I0. 
Table 2 Review of stapling device-tissue interactions and potential information required to address the existing surgical knowledge gap

\begin{tabular}{|c|c|c|}
\hline Device tissue interactions & Device group: stapling & Potential research questions \\
\hline \multicolumn{3}{|l|}{ Device } \\
\hline Unit: "what it is" & Staple & $\begin{array}{l}\text { What should a staple look like when the stapler is } \\
\text { deployed? How does the staple shape affect outcomes? }\end{array}$ \\
\hline Outcome: "what it does" & Staple line & $\begin{array}{l}\text { What does an optimal staple line look like? How many } \\
\text { rows are "right"? }\end{array}$ \\
\hline Embodiments: "what performs it" & $\begin{array}{l}\text { Gastrointestinal anastomotic } \\
\text { staplers/skin staplers/linear } \\
\text { staplers/circular staplers/curved } \\
\text { cutters/articulation linear cutters }\end{array}$ & $\begin{array}{l}\text { How does performance vary from a stapler to a cutter } \\
\text { in staple formation? Which staplers offer less risk of } \\
\text { stricture formation? Which staplers/cutters offer less risk } \\
\text { of anastomotic leakage? }\end{array}$ \\
\hline \multicolumn{3}{|l|}{ Tissue } \\
\hline Properties: "what can be affected" & Mechanical/biochemical & $\begin{array}{l}\text { How do the components (air, liquid, and solid) and } \\
\text { nature of tissue affect staple formation? }\end{array}$ \\
\hline $\begin{array}{l}\text { Perfusion: "what should not be } \\
\text { affected" }\end{array}$ & Adequate/inadequate & $\begin{array}{l}\text { How much blood flow is right for stapled tissue? How } \\
\text { can we judge appropriate perfusion? Which tissues are } \\
\text { most sensitive to ischemia? }\end{array}$ \\
\hline \multicolumn{3}{|l|}{ Interaction } \\
\hline Dynamics: "what is affected" & Compression/tension & $\begin{array}{l}\text { What is the value of compression in stapling? How much } \\
\text { tension is too much? How much of a load does tissue } \\
\text { impart on devices? What is the staple line tensile strength } \\
\text { after healing? Which stapler cartridges should I utilize } \\
\text { for bronchial cartilage versus the parenchyma? How do } \\
\text { I minimize the trauma to the surrounding tissues? }\end{array}$ \\
\hline
\end{tabular}

Note: Reproduced from Chekan E, Whelan RL, Feng AH. Device-tissue interactions: a collaborative communications system. Ann Surg Innov Res. 20 I3;7(I): 10. ${ }^{2}$

instruments (advantageous from the viewpoint of sterility). Also, staplers have been developed for use in either open or minimally invasive procedures.

Most modern staplers bend each staple into a B-shape staple form, which helps to secure the tissue in place. However, malformed staples can occur because staple leg bending depends on a number of tissue/stapler characteristics including tissue thickness, tissue viscosity, staple height, and other staple properties (thickness, bending characteristics, type of metal, etc). Staples are designed to form consistently, and staples that are not forming as intended should be investigated. Figure 1 provides examples of acceptable and unacceptable staple forms, as determined by a staple manufacturer (note that staplers should always be used in accordance with published indications and contraindications).

Staples in surgical staplers are made available in various sizes and heights (Table 3 ) so that the surgeon can choose the one that provides appropriate homeostasis/tissue apposition without significant ischemia or tissue destruction. ${ }^{2}$ If the closed staple height is too high, then it may inadequately appose the tissues and result in leakage, bleeding, and/or dehiscence. Conversely, if the staple height selected is too low, then ischemia, serosal shearing, or "cheese wiring" may result, potentially leading to leakage or frank necrosis. There are at least three staple heights for most linear staplers. Presently, it is our experience that staple selection is largely based on anecdotal evidence and the practices of attending surgeons passed down from teacher to student at each institution.

An example of how the choice of a particular stapler might affect surgical outcomes can be seen if the circular end to end anastomotic stapler is considered. These devices come in different diameter sizes to accommodate the variety of bowel lumen diameters encountered clinically. The effect of circular stapler lumen diameter (not staple size) on outcomes is still a matter of debate. Our literature search found 17 publications addressing this topic; ${ }^{5-21}$ however, many of the outcomes measures considered (hemorrhage, leak, weight loss) were not significant or did not show consistent trends from study to study. For example, Kim et al reported that use of a $25 \mathrm{~mm}$ diameter circular stapler was a risk factor for gastric stasis during the early postoperative period (eg, 6 months) when compared to results obtained with a $29 \mathrm{~mm}$ diameter circular stapler. However, the $29 \mathrm{~mm}$ stapler was found to be a risk factor for bile reflux, gastritis, and esophagitis in the late postoperative period (eg, 12 months). ${ }^{5}$ Of note, prior studies did not show significance in regards to these or similar outcomes measures. The only exception to this lack of concordance is that there was a consistent trend across 12 studies towards increased stenosis and stricture with a smaller lumen stapler. Thus, the clinical data are often very difficult to interpret; the ideal stapler 

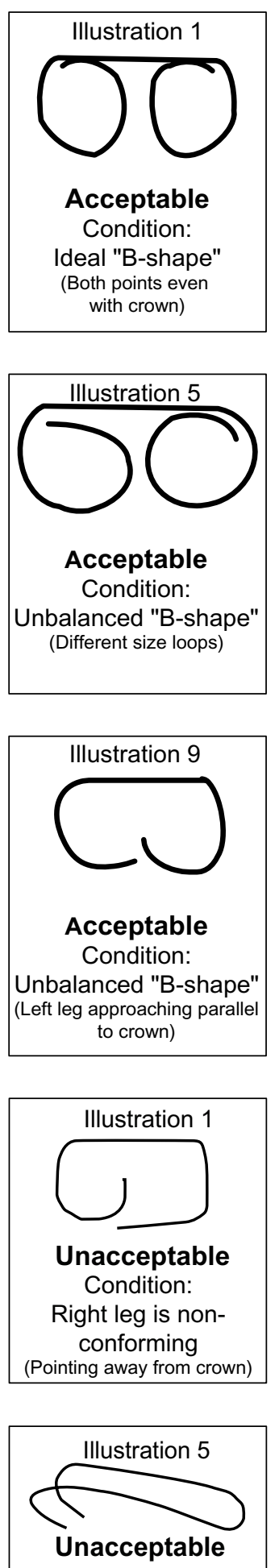

Condition:

Both legs are nonconforming

(Legs partially formed crown folded)
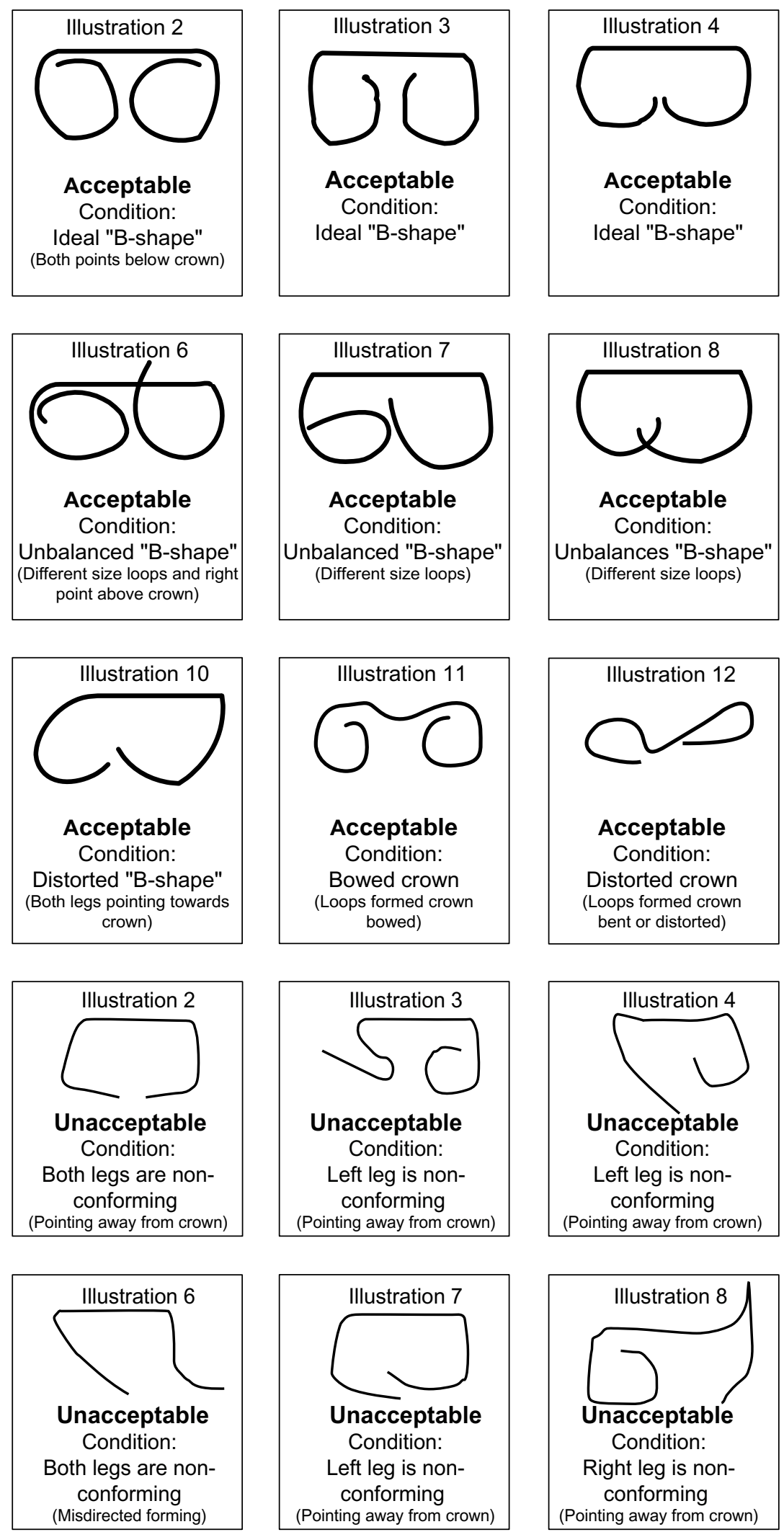

Figure I Acceptable and unacceptable staple forms produced after firing of staples into tissue to create an anastomosis.

Note: Presence of unacceptable forms can compromise integrity and strength of the staple line resulting in an increased rate of leaks and bleeding. Reprinted from Am J Surg. Akiyoshi T, Ueno M, Fukunaga Y, et al. Incidence of and risk factors for anastomotic leakage after laparoscopic anterior resection with intracorporeal rectal transection and double-stapling technique anastomosis for rectal cancer. 201 I;202(3):259-264. Copyright (c) 20II, with permission from Elsevier. ${ }^{60}$ 
Table 3 Dimensions of commonly available staple cartridges that are used to accommodate different tissue thicknesses for appropriate tissue management

\begin{tabular}{lllll}
\hline Color & Rows & $\begin{array}{l}\text { Tissue } \\
\text { type }\end{array}$ & $\begin{array}{l}\text { Open staple } \\
\text { height }\end{array}$ & $\begin{array}{l}\text { Closed } \\
\text { staple height }\end{array}$ \\
\hline Grey & 6 & Mesentery & $2.0 \mathrm{~mm}$ & $0.75 \mathrm{~mm}$ \\
White & 6 & Vascular & $2.5 \mathrm{~mm}$ & $1.0 \mathrm{~mm}$ \\
Blue & 6 & Standard & $3.5 \mathrm{~mm}$ & $1.5 \mathrm{~mm}$ \\
Gold & 6 & $\begin{array}{l}\text { Standard/ } \\
\text { thick }\end{array}$ & $3.8 \mathrm{~mm}$ & $1.8 \mathrm{~mm}$ \\
Green & 6 & Thick & $4.1 \mathrm{~mm}$ & $2.0 \mathrm{~mm}$ \\
\hline
\end{tabular}

type may vary based on which outcome measure is assessed (stenosis versus bile reflux).

\section{Tissue properties}

The unique properties of the different types of tissues in the body have a major impact on the choice of a stapler and staple height. Different tissues in the body vary in thickness, and dimensions may change based on sex, age, organ/ system/anatomical structure, age, location within an organ, preoperative therapies, intraoperative medications, and the disease state. Furthermore, tissue has a biphasic nature due to having both liquid and solid properties, and different tissue types have inherently different ratios of liquid and solid components as well as air components. In addition to these intrinsic mechanical tissue properties that help to differentiate tissue, intrinsic biochemical properties such as the protein content and metabolic profile are also differentiating factors. Moreover, the extrinsic blood supply will also vary by tissue type and contributes further to differentiation. The compressive load necessary to form a stable anastomosis will depend on these inherent tissue properties, as well as the current physical condition of the tissues to be joined, and is of paramount importance for achieving adequate perfusion and healing as well as to limit ischemia/tissue destruction. Optimal stapling of any tissue requires an adequate tissue compression time (to decrease the fluid in the tissue) to allow elongation of the tissue being compressed, smooth firing of the instrument, and consistent staple line formation; this need must be balanced against the risk of increased tissue tearing and excessive tensile strength. ${ }^{2}$

\section{Device-tissue interactions}

It is important to realize that the principles of tissue biomechanics that are important for stapling also apply to hand sewn anastomoses. ${ }^{22}$ One of the critical biomechanical variables to consider when joining two tissues together is the degree of compression applied. The optimal amount of compression for a particular tissue will largely depend on the tissue's mechanical properties. The biphasic nature of human tissue, its inherent compressibility, and differences in thickness all work together to produce a viscoelastic response when tissue is placed under a compressive force. Consequently, tissue properties will change over time as the tissue is compressed, resulting in changes such as tissue elongation and stress relaxation. ${ }^{2}$ In addition to the impact of tissue thickness on compression, the inherent elasticity of the tissue in question is also an important variable. ${ }^{2}$ The force and duration of compression ideally will result in optimal tissue compression and elongation such that the staple line will be hemostatic and well perfused without the development of tissue shearing. ${ }^{2}$

There are published data concerning device-tissue interactions that demonstrate the importance of the biomechanical factors and variables mentioned above, including compression. As early as the 1960s, Astafiev's experiments with stapling devices of his era demonstrated that "The defined values of isolated organ walls cannot serve as initial data for estimation of suturing gap range in instruments, for they do not include the tissue turgor that depends on blood filling, tissue fluid pressure, and other factors." ${ }^{23}$ Consequently, each tissue type must be appropriately compressed before suturing or stapling to achieve the optimal amount of perfusion and homeostasis for healing. More recent studies lend further support to the concept that increased compression is associated with desirable outcomes: lower leak rates ${ }^{24}$ increased intraluminal pressure, ${ }^{25}$ improved hemostasis,${ }^{24}$ and minimized wound contraction, potentially leading to decreased stricture rates..$^{24,26,27}$

The mechanical properties of tissues are also influenced by inherent patient differences including specific tissue location, accessibility, comorbidities, prior medications/therapy, and the pathological condition of the tissue. Differences in the profile for each patient in regards to this list of variables not only influence the tissue thickness but also its compressibility. For example, the changes in thickness associated with irradiation may alter the inherent compressibility of the tissue. As the tissue becomes less compressible, an increased amount of pressure needs to be applied by the stapler to the tissue to ensure that the desired closed staple height is obtained. All stapler reloads are indicated for a specific closed staple height; the tissue is also compressed 
to the same height. Surgeons must be aware that the choice of staple cartridge (staple height) will determine the amount of compression imparted upon the tissue when the stapler is closed and fired.

Numerous studies performed with various tissue types (gastric, ${ }^{28}$ colorectal, ${ }^{1}$ and pancreatic ${ }^{29}$ ) provide data that demonstrate the importance of a surgeon's familiarity with tissue thickness and compressibility in order to optimize stapler-tissue interaction. The most robust papers examining the relationship between outcomes and compression come from the bariatric literature, where the results obtained with staples of different lengths have been compared. Three studies which collectively assessed more than 4,000 patients came to the same conclusion; namely, that more compression is advantageous and that a smaller staple height was associated with a lower incidence of hemorrhage and stenosis/stricture. ${ }^{24,26,27}$ The largest of these studies also noted a trend toward a decreased leak rate in the shorter staple subgroup. ${ }^{24}$

In addition to the magnitude of the compressive force, compression time is another important variable. Using a linear stapler, Nakayama et al showed in stomach tissue that there was a relationship between the amount of time a tissue was compressed and optimal (defined as a well formed closed staple) staple formation. ${ }^{30}$ Increasing precompression times both decreased staple height and increased optimal staple formation rate. In a separate study, Nakamura et al reported that prolonged perifiring compression with a linear stapler effectively prevented pancreatic fistula formation and reduced the length of stay following laparoscopic distal pancreatectomy. ${ }^{31}$ It is important to note that while compression is a key factor in maintaining staple line integrity, excessive compression must be avoided to prevent ischemia and tissue destruction. $^{2}$

\section{Surgeon educational gap}

Formal testing has recently revealed that there are knowledge gaps in many surgeons' understanding of the safe use of many commonly used medical devices. Such deficiencies have led to the creation of educational programs. For instance, The Society of Gastrointestinal and Endoscopic Surgeons has begun to fill this gap for energy devices with a well-developed online curricula, a textbook (Fundamental Use of Surgical Energy ${ }^{\mathrm{TM}}$ ), and a validated examination based on content derived from the collaboration of health care professionals and representatives from industry. ${ }^{32,33}$
Similar, albeit less formal, efforts have been undertaken for surgical stapling. McColl et al created a multiple-choice test to assess general surgery residents' knowledge on the purpose and function of linear, circular, and laparoscopic staplers. ${ }^{34}$ The test was administered both before and after a 40-minute didactic teaching lecture delivered through a collaborative effort between an attending general surgeon and industry representative with comprehensive knowledge of stapling devices. Mean test scores significantly increased from 53\% (pretest) to $77 \%$ (posttest), $(P<0.05)$. In this small group $(n=26)$, this study again identifies a significant gap in existing stapling knowledge and showed the feasibility and value of industry-surgeon collaboration to develop an effective educational program for clinicians.

As shown, many device-associated variables, such as stapler diameter, staple size, tissue location, and compression time as well as tissue variables (ie, tissue thickness and compressibility), can affect the integrity of the staple line and patient outcomes. However, all these factors must be considered in the context of perhaps the most relevant variable: the experience and surgical technique of the surgeon.

When trying to decrease anastomotic leak rates for instance, Çakabay et al emphasized the importance of meticulous technique and suggested a protocol-driven approach. ${ }^{35}$ Additional studies also support the concept that a surgeon's experience with a given device is a key determinant in patient outcomes. A review of operative reports and web-based charts for colon and rectal resections at Brigham and Women's Hospital (Boston) found that $19 \%$ of these procedures featured a technical error involving the stapling device. ${ }^{1}$ Errors included (but were not limited to) surgeon misfiring, incomplete anastomosis (inadequate donuts, staple line defects, or primary device failure), and were associated with a significantly $(P<0.03)$ increased risk of gastrointestinal bleeding, transfusions, and unplanned proximal diversions. Similarly, a review published over two decades ago of anastomoses made during esophageal resections at the Royal Victoria Hospital (Belfast) concluded that although stapling devices brought uniformity to the creation of anastomoses, they "cannot compensate for deficiencies in surgical technique" and further commented that advances in technology "cannot overcome deficiencies in technique such as indelicate handling of the tissues, tension on anastomoses, ischemic anastomoses, and the attempted salvage of unsatisfactory 
anastomoses rather than takedown and construction of a second anastomosis". ${ }^{36}$

A surgeon's understanding of the interplay of devices and tissues coupled with sound surgical technique are important elements in the formula for predictable, favorable patient outcomes.

\section{Methods}

\section{Published literature search strategy}

A search of the medical literature using MEDLINE ${ }^{\circledR}$, EMBASETM $^{\mathrm{T}}$, and the Knove ${ }^{\circledR}$ Technology Database was conducted for the period of January 1988-November 2012 to identify published articles and electronic book chapters related to surgical device-tissue interactions, surgical staplers, and the use of surgical staplers in thoracic, bariatric, and colorectal surgical procedures. The full articles were retrieved and manually filtered in order to identify relevant articles. Additional references were identified from the reference lists of the filtered articles.

We focused primarily on studies that reported data from relatively smaller patient populations because these studies typically disclosed the specific devices used during the surgical procedure, whereas larger patient studies often did not report this information as they generally focused on the surgical techniques.

We will now focus on three specialties that commonly utilize stapling devices and will present the available data with respect to device-tissue interaction in these arenas.

\section{Specialty specific device-tissue interaction considerations \\ Bariatric surgery}

Staple line integrity is a major priority in bariatric surgery. Leaking staple lines and hemorrhage are associated with considerable morbidity and, in some cases, mortality. The overall incidence of bariatric surgical complications is reported to be $<10 \%$ and the incidence of postoperative bleeding about $3 \% .{ }^{37}$ The incidence of potentially lifethreatening, permanently disabling, or fatal complications varies depending on the particular procedure done; for gastric bypass surgery, sleeve gastrectomy, and adjustable gastric band, the rate of these types of complications are $3.6 \%$ versus $2.2 \%$ versus $0.9 \%$, respectively $(P<0.001$ for all). ${ }^{38}$

When considering device-tissue interactions in the field of bariatric surgery, a strong familiarity and understanding of the stomach is of critical importance. The stomach is an example of an organ whose tissue thickness varies considerably from location to location; this characteristic will influence the performance of staplers. Mean stomach wall thickness measurements range from 1.6 to $3.1 \mathrm{~mm}$ (maximum values range from 2.2 to $4.5 \mathrm{~mm}$ ), with thickness typically increasing as one moves from the esophageal gastric junction to the pylorus. Moreover, thickness is reduced along the axis of the stomach and toward the greater curvature versus the lesser curvature. $^{28}$

The varying tissue thickness of the stomach mandates that the surgeon carefully consider the specific location of the planned staple line, as this will influence the choice of staple size. ${ }^{28}$ For example, use of a staple that is "too small" in the prepyloric region of the stomach can lead to excessive tissue compression or inadequate staple formation. This could ultimately lead to tearing of the tissue or even staple line failure. Thus, it may not be surprising that, in the authors' experience, most surgeons use staples with longer leg heights when stapling on the distal stomach as compared to the more proximal stomach.

The importance of choosing the most appropriate staple size was demonstrated in a retrospective study of patients who had laparoscopic Roux-en-Y gastric bypass surgery. Patients who had an anastomosis constructed with a circular stapler (Covidien EEA 2535; 25 mm diameter anvil; Mansfield, MA, USA) that fired staples having a $3.5 \mathrm{~mm}$ open staple height had a significantly lower rate of stricture requiring dilatation than those in whom a circular stapler (Covidien EEA25; $25 \mathrm{~mm}$ diameter anvil) firing staples with $4.8 \mathrm{~mm}$ open staple height was utilized $(6.1 \%$ versus $15 \%$, $P=0.01)$. Of note, the rate of leakage and abscess formation for the small and large staple anastomoses was similar. ${ }^{26}$ A larger study comparing a series of 1,074 patients who had undergone Roux-en-Y gastric bypass using a circular stapler (Covidien DST Series EEA; $25 \mathrm{~mm}$ diameter anvil) that fired staples with a $3.5 \mathrm{~mm}$ open staple height with another series of 2,606 patients treated using a circular stapler (Covidien Premium Plus CEEA; $25 \mathrm{~mm}$ diameter anvil) firing staples with a $4.8 \mathrm{~mm}$ open staple height noted significantly lower rates of hemorrhage $(0.37 \%$ versus $2.45 \%, P<0.001)$ and insignificantly lower rates of leak and stenosis for the smaller staple size group. ${ }^{24}$ It is important to note that these results demonstrate an association between staple size and outcome; however, since the studies were not randomized and because the tissue thickness in each case is unknown, it is not possible to attribute the improved results to the use of the smaller staple height. It should be mentioned that the 
main difference between the circular staplers on the market presently is that the Covidien EEA has a fixed open staple height of $3.5 \mathrm{~mm}$ (closed staple height $1.5 \mathrm{~mm}$ ) or $4.8 \mathrm{~mm}$ (closed staple height $2.0 \mathrm{~mm}$ ) whereas the Ethicon $\mathrm{CDH}$ (Ethicon Inc., Somerville, NJ, USA) has a variable staple height range (ie, open staple height of $5.5 \mathrm{~mm}$ with a gap setting that can be adjusted to control for a closed staple height from 1.0 to $2.5 \mathrm{~mm}$ ). The abovementioned studies emphasize the importance of understanding the relationship of tissue compression with closed staple height.

\section{Colorectal surgery}

In colorectal surgery, anastomotic leakage (reported incidence varying from 0 to as high as $30 \%{ }^{39}$ ) is a major issue due to the increased risk of associated complications, the potential need for additional operative procedures, extended hospital stays, and increased morbidity and mortality rates. Anastomotic leakage rates vary from the colon to the rectum, with much higher rates in the rectum. Anastomotic leaks may affect long-term outcomes and have been associated with an increased prevalence of locoregional recurrence in cancer patients ${ }^{40,41}$ and poor functional results in patients undergoing low anterior resection. ${ }^{42}$

As in bariatric surgery, tissue thickness is an important consideration in colorectal cases. The normal uncompressed thickness of the small intestine wall typically measures between 1 and $2 \mathrm{~mm}$ (distended lumen), whereas the colon wall may be up to $3 \mathrm{~mm}$ thick (distended). ${ }^{43}$ Bowel wall thickening can occur in pathological situations. Mild thickening of $<2 \mathrm{~mm}$ may occur from infectious enterocolitis, ulcerative colitis, Crohn's disease, radiation injury, ischemia, diverticulitis, edema, or submucosal hemorrhage. More marked thickening of $>2 \mathrm{~mm}$ can result from adenocarcinoma, gastrointestinal stromal tumor, metastases, lymphoma, severe colitis, severe diverticulitis, or systemic lupus erythematosus. ${ }^{43}$ As observed for other tissues, understanding how these conditions can influence properties such as tissue thickness and compressibility is paramount if the surgeon is to select the most appropriate anastomotic method (staple versus hand sewn), and if a stapled anastomosis is to be constructed, the best stapler (linear versus circular) and staple height to obtain the best possible surgical outcome.

Anastomosis following rectal resection presents the surgeon with the additional technical challenge of rejoining the bowel deep in the pelvis, where access is difficult because of the bony confines. Further, linear transection of the distal rectum to remove the specimen is also quite challenging, especially in the narrow, deep male pelvis. When using laparoscopic methods, two or more staple firings may be required to transect the rectum. Further, because it is difficult to place the linear staplers at right angles to the axis of the rectum in the deep pelvis, the staple line may be long and oblique; at least one author suggests that this issue may increase the risk of anastomotic leak. ${ }^{44}$

Curved or radial staplers have been developed as an alternative to the standard straight, linear stapler to facilitate division of the distal rectum. These staplers have gently arched end effectors, and the final result is a curved staple line. The slightly rounded stapler head has a narrower profile than a standard linear stapler of the same length, and this feature facilitates placement of the device into the deep pelvis, while preserving staple line length. This type of stapler lays down three rows of staples and transects the rectum between the second and third staple rows. This obviates the need to manually divide the rectum with a scalpel after using a standard transverse stapler (eg, Ethicon PROXIMATE ${ }^{\circledR}$ TX or Covidien DST Series ${ }^{\mathrm{TM}}$ TA type). Mari et al integrated the use of a curved stapler into their procedure for laparoscopic lower anterior rectal resections, ${ }^{45}$ and they reported no intraoperative or postoperative bleeding and only two leaks among the 45 patients in the series.

A patient's comorbidities can influence tissue properties and should be taken into consideration. For instance, it is well known that diabetes mellitus can change the microvascular properties of the tissue and that corticosteroid use is associated with a higher rate of anastomotic leaks. If the thickness of the bowel is impacted by these comorbidities, then the surgeon should recognize this fact and make the selection of staple height and technique (hand sewn versus stapled) with this in mind. However, it is not clear if, and how, specific comorbidities affect tissue compressibility or elasticity. Presently, surgeons may choose to proximally divert the higher risk patient with multiple comorbidities after constructing an anastomosis in order to lower the chance of a symptomatic leak forming. Although there are no supportive data or guidelines presently, it seems reasonable to take comorbidities into account when attempting to predict a given device tissue interaction.

Other risk factors for anastomotic leakage after laparoscopic intracorporeal colorectal anastomosis (Table 4) have been published. Kim et al reviewed patients over a 2-year period who had undergone laparoscopic sigmoidectomy and anterior resection using a double-stapling technique for distal sigmoid and rectal cancers. ${ }^{15}$ In this series, they found 
Table 4 Univariate and multivariate analyses for factors potentially contributing to anastomotic leakage after laparoscopic colorectal anastomosis

\begin{tabular}{|c|c|c|c|c|c|c|}
\hline \multirow[t]{2}{*}{ Characteristic } & \multirow{2}{*}{$\begin{array}{l}\text { Number of anastomotic } \\
\text { leakage/total patients }\end{array}$} & \multirow[t]{2}{*}{$\%$} & \multirow{2}{*}{$\begin{array}{l}\begin{array}{l}\text { Univariate } \\
\text { analysis }\end{array} \\
P \text {-value }\end{array}$} & \multicolumn{3}{|c|}{ Multivariate analysis* } \\
\hline & & & & Hazard ratio & $95 \% \mathrm{Cl}$ & $P$-value \\
\hline \multicolumn{3}{|l|}{ Age, years } & 0.996 & & & \\
\hline$\leq 60$ & $7 / 123$ & 5.7 & & 1.00 & - & \\
\hline$>60$ & $10 / 147$ & 6.8 & & 1.34 & $0.44-4.05$ & 0.606 \\
\hline \multicolumn{3}{|l|}{ Sex } & 0.209 & & & \\
\hline Female & $4 / 105$ & 3.8 & & 1.00 & - & \\
\hline Male & $13 / 165$ & 7.9 & & 1.84 & $0.50-6.81$ & 0.364 \\
\hline \multicolumn{3}{|l|}{ BMI, kg/m² } & 0.572 & & & \\
\hline$\leq 25$ & $\mathrm{I} \mid / 204$ & 5.4 & & 1.00 & - & \\
\hline$>25$ & $6 / 66$ & 9.1 & & 1.62 & $0.5 \mathrm{I}-5.14$ & 0.413 \\
\hline \multicolumn{3}{|l|}{ Previous laparotomy } & 1.000 & & & \\
\hline No & $15 / 234$ & 6.4 & & 1.00 & - & \\
\hline Yes & $2 / 36$ & 5.6 & & 1.52 & $0.28-8.39$ & 0.631 \\
\hline \multicolumn{3}{|l|}{ ASA score } & 0.655 & & & \\
\hline 1 & $14 / 198$ & 7.1 & & & & \\
\hline 2 & $3 / 69$ & 4.3 & & & & \\
\hline 3 & $0 / 3$ & 0 & & & & \\
\hline \multicolumn{3}{|l|}{ Tumor location } & 0.021 & & & \\
\hline Sigmoid colon & $5 / 165$ & 3.0 & & 1.00 & - & \\
\hline Upper rectum & $5 / 47$ & 10.6 & & 3.27 & $0.8 I-13.16$ & 0.095 \\
\hline Middle/lower rectum & $7 / 58$ & 12.1 & & 5.44 & $1.44-20.66$ & 0.013 \\
\hline \multicolumn{3}{|l|}{ Tumor, cm } & 0.202 & & & \\
\hline$\leq 3$ & $10 / 112$ & 8.9 & & 1.00 & - & \\
\hline$>3$ & $7 / 158$ & 4.4 & & 0.70 & $0.22-2.21$ & 0.538 \\
\hline \multicolumn{3}{|l|}{ Operation time, $\min$} & 0.025 & & & \\
\hline$\leq 200$ & $3 / 119$ & 2.5 & & 1.00 & - & \\
\hline$>200$ & $|4 / 15|$ & 9.3 & & 1.45 & $0.32-6.61$ & 0.632 \\
\hline \multicolumn{3}{|c|}{ Length of Ist cartridge, $\mathrm{mm}$} & 1.000 & & & \\
\hline 60 & $13 / 202$ & 6.4 & & 1.00 & - & \\
\hline 45 & $4 / 68$ & 5.9 & & 0.88 & $0.21-3.74$ & 0.858 \\
\hline \multicolumn{3}{|l|}{ Number of stapler firings } & 0.04 & & & \\
\hline 1 & $1 / 92$ & I.I & & 1.00 & - & \\
\hline 2 & $13 / 146$ & 8.9 & & 6.69 & $0.80-56.01$ & 0.080 \\
\hline$\geq 3$ & $3 / 32$ & 9.4 & & 6.60 & $0.52-84.11$ & 0.146 \\
\hline \multicolumn{3}{|c|}{ Diameter of circular stapler, mm } & 0.022 & & & \\
\hline 25,29 & $3 / 123$ & 2.4 & & 1.00 & - & \\
\hline 31,33 & $14 / 147$ & 9.5 & & 3.73 & $0.77-18.19$ & 0.104 \\
\hline \multicolumn{3}{|l|}{ Stage } & 1.000 & & & \\
\hline I-II & $10 / 153$ & 6.5 & & 1.00 & - & \\
\hline III-IV & $7 / 117$ & 6.0 & & 1.04 & $0.35-3.08$ & 0.949 \\
\hline
\end{tabular}

Notes: *Calculated by logistic regression. Reprinted from J Am Coll Surg. Kim JS, Cho SY, Min BS, Kim NK. Risk factors for anastomotic leakage after laparoscopic intracorporeal colorectal anastomosis with a double stapling technique. 2009;209(6):694-70I. Copyright (C) 2009, with permission from Elsevier. ${ }^{15}$

Abbreviations: ASA, American Society of Anesthesiologists; BMI, body mass index; $\mathrm{Cl}$, confidence interval.

that repeated applications of linear staplers to transect the rectum distally was a significant risk factor $(P=0.04)$ for anastomotic leakage. Furthermore, in a univariate analysis, the use of circular staplers with large diameters (ie, 31 and $33 \mathrm{~mm}$ ) was associated with a significantly higher rate of anastomotic leakage after laparoscopic rectal transection versus results with the smaller diameter staplers $(P=0.022)$. The authors speculated that a larger diameter circular stapler may cause the distal remnant rectum to be more distended and, consequently, make the rectal wall thinner and decrease blood supply to the stapled anastomosis.

To emphasize the importance of proper surgical training and experience in achieving good surgical outcomes, Detry et al published a review of 1,000 consecutive colorectal anastomoses performed by a single surgical team between 1979 and 1992 and suggested that stapled anastomoses were 
safe and reliable if the staplers were properly utilized and the steps of the procedure standardized. ${ }^{46}$ Several authors report that procedural innovation and a fundamental understanding of surgical stapling devices are important in achieving good patient outcomes. ${ }^{45,47}$

\section{Thoracic surgery}

Vital structures, such as the pulmonary arteries, bronchi, and the vagus nerve and its branches, must be considered when using staplers in the chest.

Similar to colorectal and gastric tissues, lung tissue also varies in thickness and compressibility. The inherent air content of the lungs make them even more variable in thickness than many other tissues. Difference in tissue properties also extend to the biochemical makeup of lung tissue. For instance, it is known that lung tissue has a natural elasticity due to its higher proportion of elastin. This affects the tissue's properties and likely changes it viscoelastic behavior and, consequently, the ideal compression time and degree of compression.

To this end, the location of the lesion within the lung must be taken into account. For example, if stapling is performed in the periphery of the lung, where there is more air than solid or liquid components, then adequate compression requires less pressure and a shorter prefiring compression time. In contrast, the more centrally located lung tissue contains more fluid (blood) and solid components (bronchial cartilage). Consequently, longer compression times and taller staples are required to obtain a well formed staple line and to maintain staple line integrity. ${ }^{48}$

Another variable is the pathological state of tissue, ie, diseased or normal. Increases in thoracic tissue thickness are observed for a number of pathological conditions including lung carcinoma, pulmonary fibrosis, and asbestosis. Conditions such as emphysema and tuberculosis can also affect tissue and outcomes. For example, emphysematic tissue is often characterized as containing less protein, which can make it more difficult to achieve aerostasis. ${ }^{49}$ In fact, Hunt and Aye showed that patients with emphysema are at the highest risk of air leak. ${ }^{50}$ Furthermore, because of destruction of connective tissue and increased compliance, there may be an increased risk of tissue tearing adjacent to staple lines, ${ }^{51}$ which may delay healing after surgery. ${ }^{52}$

The development of a bronchopleural fistula is a major complication associated with thoracic surgery. Although the incidence of these fistulas after pneumonectomy is reported to be lower after stapling $(2.0 \%-5.2 \%)$ versus hand suturing $(6.6 \%-18.2 \%),{ }^{53}$ techniques to further reduce the rate of fistula formation would, if successful, improve patient outcomes. Aoki et al noted that when fistulas develop after stapling the main bronchus, the specific site of the fistula is the stump's center; they hypothesized that there was increased tension in the membranous part of the bronchus in this location due to compression by the stapler. ${ }^{53}$ They conducted a small study in patients undergoing pneumonectomy wherein the conventional procedure was modified by folding both sides of the cartilaginous wall while stapling, thereby reducing the tension, and then not covering the stump afterwards. None of the patients developed a fistula although a larger study is required to confirm these results.

The introduction of video-assisted thoracic surgery (VATS) methods over the past 20 years has greatly changed thoracic surgery. VATS methods allow for minimally invasive treatment of benign and malignant pulmonary lesions, lung volume reduction surgery, decortication, mediastinal mass removal, evacuation of fluid or infectious tissue from the pleural cavity, and diaphragmatic plication. Compared with open procedures, the benefits of VATS include shorter hospital stays and less postoperative pain, morbidity, narcotics usage, and scarring. ${ }^{54-57}$ Unfortunately, there are minimal published data specific to device-tissue interactions in this area. What is clear, however, is that technique still matters.

A review of all thoracoscopic procedures performed by Gossot et al over a 1-year period was conducted to determine the rate of adverse events related to the use of an endostapler during VATS.$^{58}$ Both a database and recorded videotapes of the procedures were evaluated. Their review of 434 staple firings carried out on 130 patients showed that some adverse events were attributed to surgical errors; however, others were attributed to the stapling device, ie, oozing (13 cases), active hemorrhages on staple line (five cases), partial or total disruption of the staple line (13 cases versus one case), and technical device malfunctions (two cases). ${ }^{58}$ They determined that 34 out of 434 (7.6\%) stapler firings resulted in a minor or major problem; this incidence is higher than that noted in patients undergoing similar open thoracic operations. In 12 cases, no specific action was required, whereas in 22 cases the resulting problem mandated repair. They speculated that there were three reasons for the increased incidence of stapler-associated problems in VATS versus open lung resection: 1) indecision in choosing between the 3.5 and $4.5 \mathrm{~mm}$ staple height due to difficulty in appreciating both 
the thickness and resistance of lung tissue in the minimally invasive setting, 2) the relatively small jaw opening of endostapler can make loading of the tissue difficult and may create friction and lead to tearing of the tissue, and 3) difficulty in precisely positioning the stapler tip may result in excessive traction being placed on the tissue. ${ }^{58} \mathrm{~A}$ key message was that adverse events were attributable to both surgical errors as well as device-related errors. Training and educational programs should help to reduce the incidence of surgical errors, whereas improvements by manufacturers in staple design would help reduce device errors and complications.

\section{Discussion}

One unintended consequence of the rapid technological advancements that have facilitated the development of numerous classes of surgical devices is the inherent difficulty many surgeons face in staying up-to-date on the proper use of a given device. To fill in the present knowledge gap, a literature review focused on surgical stapling over the last two decades was carried out. During this time frame, many minimally invasive surgical stapling devices have been designed, developed, and redesigned, with second and third generation minimally invasive surgical staplers now being commonplace. Even with these newer devices, use should be in accordance with indications and contraindications, as not all staplers can be used in all situations. (For example, a circular stapler can be more useful in a low anterior resection, where it can be used to preserve rectal function, as compared to use in a right colon resection.)

Creating a staple line that maintains proper tissue apposition while enabling appropriate homeostasis and tissue perfusion, minimizing excessive bleeding and tissue destruction, and eliminating or limiting the number of postoperative leaks are the primary goals of any stapling procedure. The most important factor in creating the optimal staplertissue interaction (defined as formation of an optimal staple line with well-formed staples, good vascularization, and the absence of tissue tearing) is compression of the tissue. The tissue thickness and its intrinsic mechanical properties will determine the necessary amount of compressive force and the adequate length of prefiring compression time. The correct staple height will therefore vary depending on these tissue-specific properties.

An understanding of how stapling devices interact with their target tissues is key to improving patient outcomes. The majority of studies evaluated in this review reinforce the common theme that although factors such as compression, staple height, tissue thickness, and tissue type must all be considered, the experience of the surgeon is the common denominator integrating these factors to ultimately create a staple line with good integrity that resists leakage while promoting proper wound healing. Consequently, educational programs designed to keep surgeons up to date regarding the optimal use of staplers need to be established and made readily available to the surgical community. Obviously, these educational programs would also greatly facilitate the teaching of residents and would likely become mandatory training for junior residents prior to their first use of staplers in a clinical case.

The current review focused on bariatric, thoracic, and colorectal studies. It was shown that different types of tissues have different thicknesses and biomechanical properties that may require the use of staples of different heights or the use of a different type of stapler (linear versus curved versus circular) to construct a stable anastomosis. Each tissue type has its own challenges, and the pathology of the tissue must also be taken into account. For example, the stomach demonstrates wide variations in tissue thickness, and these differences must be taken into account when choosing the staple size in order to create an anastomosis with good staple line integrity that will prevent leakage of gastric contents. Colorectal tissue has a more uniform thickness when compared with gastric tissue; however, a number of risk factors such as poor vascularity, tension, and variable tissue thickness can increase the incidence of colorectal staple line leaks. Furthermore, accessibility issues, especially in the male pelvis, make distal transection of the rectum a challenge. The narrow confines of the distal pelvis may mandate the placement of the linear stapler at an angle oblique to the longitudinal axis of the rectum instead of at a 90-degree angle, which results in a longer angled staple line and the need for multiple cartridges to fully transect the bowel. The generous use of diverting ileostomy or colostomy in patients with distal double-stapled colorectal anastomoses is acknowledgment of the technical challenges posed by the narrow pelvis and the perceived increased risk of constructing a circular staple line across an obliquely angled, irregular, linear staple line. The modification of accepted technique, for example, the use of the triple-stapling method to transect the distal rectum to reduce the chances of stool contamination, may lower leak rates and improve outcomes. The stapling of lung tissue is uniquely challenging because of the structural complexity of this 
organ and the fact that the peripheral and central areas of the lung vary greatly in regards to its solid (bronchi) and more plastic elements (alveoli). Bronchial fistula development is a major potential complication of thoracic stapling. Newly developed stapling techniques, as well as the use of different stapler designs, hold the promise of reducing the incidence of this feared complication.

Bringing the surgical community together with other professionals in the device industry, such as stapler manufacturers, engineers, and scientists, to collaborate on the development of educational programs to keep surgeons apprised of the optimal use of medical devices should be a national priority. To facilitate this process, currently available data need to be collected in a principal location and critically assessed and summarized. Further, prospective databases into which surgeons can enter specific case information regarding their stapling practices (type of stapler, staple size, tissue thickness, etc) and short term clinical results (leak, bleeding, stricture, and diversion rates) need to be developed. Purposefully and carefully studying current stapling methods will, hopefully, lead to the development of more specific and scientifically based recommendations regarding the choice of staple height and best stapling methods for the diverse range of clinical situations encountered by surgeons. The ultimate goal is reduction of the complication rate and improved patient outcome. We hope that this review will increase awareness of the challenges posed by the use of staplers as well as the lack of educational programs for surgeons in training and attending surgeons.

\section{Acknowledgments}

Alan J Klopp, PhD, CMPP, of inScience Communications, Springer Healthcare, provided medical writing support funded by Ethicon. Funding for the development of the manuscript was provided by Ethicon.

\section{Disclosure}

Dr Edward Chekan is an employee of Ethicon and holds stock in Johnson \& Johnson. Dr Richard L Whelan serves as a consultant for Ethicon. The authors have no other conflicts of interest to declare.

\section{References}

1. Offodile AC, Feingold DL, Nasar A, Whelan RL, Arnell TD. High incidence of technical errors involving the EEA circular stapler: a single institution experience. J Am Coll Surg. 2010;210(3):331-335.

2. Collopy BT. Colorectal anastomotic leak rates are measures of technical skill in surgery. ANZ J Surg. 2001;71(9):508-510.

3. Baker RS, Foote J, Kemmeter P, et al. The science of stapling and leaks. Obesity surgery. 2004;14(10):1290-1298.
4. Chekan E, Whelan RL, Feng AH. Device-tissue interactions: a collaborative communications system. Ann Surg Innov Res. 2013;7(1):10.

5. Kim MK, Park JM, Choi YS, Chi KC. Smaller-diameter circular stapler has an advantage in Billroth I stapled anastomosis after laparoscopyassisted distal gastrectomy. J Laparoendosc Adv Surg Tech A. 2012; 22(3):236-241

6. Fernández-Fernández L, Tejero E, Tieso A. Influence of cartridge size on the morbidity of esophagojejunal anastomosis with EEA stapling devices. Digestive Surg. 1995;12(4):235-237.

7. Berrisford RG, Page RD, Donnelly RJ. Stapler design and strictures at the esophagogastric anastomosis. J Thorac Cardiovasc Surg. 1996;111(1):142-146.

8. Petrin G, Ruol A, Battaglia G, et al. Anastomotic stenoses occurring after circular stapling in esophageal cancer surgery. Surg Endosc. 2000;14(7):670-674.

9. Yendamuri S, Gutierrez L, Oni A, et al. Does circular stapled esophagogastric anastomotic size affect the incidence of postoperative strictures? J Surg Res. 2011;165(1):1-4.

10. Ahad AW, Tilak J, Reiss D, Pilcher J. Impact of gastro-jejunostomy diameter on complications and weight loss after Roux-en-Y gastric bypass over a 5-year period. Poster presented at Society of American Gastrointestinal and Endoscopic Surgeons Meeting, March 30-April 2, 2011, San Antonio, Texas: Poster PO46. SAGES [webpage on the Internet]. Available from: http://www.sages.org/meetings/ annual-meeting/abstracts-archive/impact-of-gastro-jejunostomydiameter-on-complications-and-weight-loss-after-roux-en-y-gastricbypass-over-a-5-year-period/. Accessed April 16, 2014.

11. Corigliano N, Veyrie N, Abdelhalim A, Stephane S, Lloret Linares C, Bouillot J. Laparoscopic degastro-gastric bypass for gastrojejunal anastomotic stricture: report of a case (video). Obes Surg. 2009;19:1072. V-1034.

12. Cottam DR, Fisher B, Sridhar V, Atkinson J, Dallal R. The effect of stoma size on weight loss after laparoscopic gastric bypass surgery: results of a blinded randomized controlled trial. Obes Surg. 2009;19(1):13-17.

13. Fisher BL, Atkinson JD, Cottam D. Incidence of gastroenterostomy stenosis in laparoscopic Roux-en-Y gastric bypass using 21- or 25-mm circular stapler: a randomized prospective blinded study. Surg Obes Relat Dis. 2007;3(2):176-179.

14. Gould JC, Garren M, Boll V, Starling J. The impact of circular stapler diameter on the incidence of gastrojejunostomy stenosis and weight loss following laparoscopic Roux-en-Y gastric bypass. Surg Endosc. 2006;20(7):1017-1020.

15. Kim JS, Cho SY, Min BS, Kim NK. Risk factors for anastomotic leakage after laparoscopic intracorporeal colorectal anastomosis with a double stapling technique. J Am Coll Surg. 2009;209(6):694-701.

16. Nguyen NT, Stevens CM, Wolfe BM. Incidence and outcome of anastomotic stricture after laparoscopic gastric bypass. J Gastrointest Surg. 2003;7(8):997-1003; discussion 1003.

17. Smith C, Garren M, Gould J. Impact of gastrojejunostomy diameter on long-term weight loss following laparoscopic gastric bypass: a follow-up study. Surg Endosc. 2011;25(7):2164-2167.

18. Suggs WJ, Kouli W, Lupovici M, Chau WY, Brolin RE. Complications at gastrojejunostomy after laparoscopic Roux-en-Y gastric bypass: comparison between 21- and 25-mm circular staplers. Surg Obes Relat Dis. 2007;3(5):508-514.

19. Takata MC, Ciovica R, Cello JP, Posselt AM, Rogers SJ, Campos GM. Predictors, treatment, and outcomes of gastrojejunostomy stricture after gastric bypass for morbid obesity. Obes Surg. 2007;17(7): 878-884.

20. Tokunaga Y, Ryo J, Kitaoka A, Yagi T, Tokuka A, Ohsumi K. Jejunal pouch to avoid stricture after esophagojejunostomy with circular stapler. J Am Coll Surg. 1999;189(5):466-469.

21. Vignali A, Fazio VW, Lavery IC, et al. Factors associated with the occurrence of leaks in stapled rectal anastomoses: a review of 1,014 patients. J Am Coll Surg. 1997;185(2):105-113.

22. Hardy KJ. Non-suture anastomosis: the historical development. Aust $N$ Z J Surg. 1990;60(8):625-633. 
23. Astafiev GV. Investigation of processes relating to tissue compression in suturing and stapling apparatus. Chirurgicheskiey Shivayushiye Apparaty. 1967;7:22-31.

24. Sakran N, Assalia A, Sternberg A, et al. Smaller staple height for circular stapled gastrojejunostomy in laparoscopic gastric bypass: early results in 1,074 morbidly obese patients. Obes Surg. 2011;21(2):238-243.

25. Myers SR, Rothermel WS Jr, Shaffer L. The effect of tissue compression on circular stapler line failure. Surg Endosc. 2011;25(9):3043-3049.

26. Hanna K, Seder CW, Chengelis D, McCullough PA, Krause K. Shorter circular staple is height associated with lower anastomotic stricture rate in laparoscopic gastric bypass. Surg Obes Relat Dis. 2012;8(2):181-184.

27. Nguyen NT, Dakin G, Needleman B, et al. Effect of staple height on gastrojejunostomy during laparoscopic gastric bypass: a multicenter prospective randomized trial. Surg Obes Relat Dis. 2010;6(5):477-482.

28. Elariny H, González H, Wang B. Tissue thickness of human stomach measured on excised gastric specimens from obese patients. Surg Technol Int. 2005;14:119-124.

29. Okano K, Oshima M, Kakinoki K, et al. Pancreatic thickness as a predictive factor for postoperative pancreatic fistula after distal pancreatectomy using an endopath stapler. Surg Today. 2013;43(2): 141-147.

30. Nakayama S, Hasegawa S, Nagayama S, et al. The importance of precompression time for secure stapling with a linear stapler. Surg Endosc. 2011;25(7):2382-2386.

31. Nakamura M, Ueda J, Kohno H, et al. Prolonged peri-firing compression with a linear stapler prevents pancreatic fistula in laparoscopic distal pancreatectomy. Surg Endosc. 2011;25(3):867-871.

32. Schwaitzberg SD, Jones DB. Don't get burned from lack of knowledge. Ann Surg. 2012;256(2):219-220.

33. Feldman LS, Fuchshuber P, Jones DB, Mischna J, Schwaitzberg SD; FUSE (Fundamental Use of Surgical Energy ${ }^{\mathrm{TM}}$ ) Task Force. Surgeons don't know what they don't know about the safe use of energy in surgery. Surg Endosc. 2012;26(10):2735-2739.

34. McColl RJ, Karmali S, Reso A, Paolucci E, Sherman V. The effect of a focused instructional session on knowledge of surgical staplers in general surgery residents. J Surg Educ. 2009;66(5):288-291.

35. Çakabay B, Aksel B, Ünal E, et al. Influence of the stapler size used in esophagojejunostomy anastomosis: anastomotic leak and strictures after total gastrectomy. Turkiye Klinikleri J Med Sci. 2012;32(2) 428-431.

36. McManus KG, Ritchie AJ, McGuigan J, Stevenson HM, Gibbons JR. Sutures, staplers, leaks and strictures. A review of anastomoses in oesophageal resection at Royal Victoria Hospital, Belfast 1977-1986. Eur J Cardiothorac Surg. 1990;4(2):97-100.

37. Karmali S, Johnson Stoklossa C, Sharma A, et al. Bariatric surgery: a primer. Can Fam Physician. 2010;56(9):873-879.

38. Birkmeyer NJ, Dimick JB, Share D, et al; Michigan Bariatric Surgery Collaborative. Hospital complication rates with bariatric surgery in Michigan. JAMA. 2010;304(4):435-442.

39. Kingham TP, Pachter HL. Colonic anastomotic leak: risk factors, diagnosis, and treatment. J Am Coll Surg. 2009;208(2):269-278.

40. Merkel S, Wang WY, Schmidt O, et al. Locoregional recurrence in patients with anastomotic leakage after anterior resection for rectal carcinoma. Colorectal Dis. 2001;3(3):154-160.

41. Bell SW, Walker KG, Rickard MJ, et al. Anastomotic leakage after curative anterior resection results in a higher prevalence of local recurrence. Br J Surg. 2003;90(10):1261-1266.

42. Nesbakken A, Nygaard K, Lunde OC. Outcome and late functional results after anastomotic leakage following mesorectal excision for rectal cancer. Br J Surg. 2001;88(3):400-404.

43. Macari M, Balthazar EJ. CT of bowel wall thickening: significance and pitfalls of interpretation. AJR Am J Roentgenol. 2001;176(5): 1105-1116.
44. Leroy J, Jamali F, Forbes L, et al. Laparoscopic total mesorectal excision (TME) for rectal cancer surgery: long-term outcomes. Surg Endosc. 2004;18(2):281-289.

45. Mari FS, Gasparrini M, Nigri G, et al. Can a curved stapler made for open surgery be useful in laparoscopic lower rectal resections? Technique and experience of a single centre. Surgeon. 2013;11 Suppl $1:$ S23-S26.

46. Detry RJ, Kartheuser A, Delriviere L, Saba J, Kestens PJ. Use of the circular stapler in 1000 consecutive colorectal anastomoses: experience of one surgical team. Surgery. 1995;117(2):140-145.

47. Edwards DP, Sexton R, Heald RJ, Moran BJ. Long-term results show triple stapling facilitates safe low colorectal and coloanal anastomosis and is associated with low rates of local recurrence after anterior resection for rectal cancer. Tech Coloproctol. 2007;11(1):17-21.

48. Pickens A. Endoscopic thoracic surgery for lung cancer: mastering tools to optimize patient outcomes; 2011. General Surgery News [webpage on the Internet]. Available from: http://www. generalsurgerynews.com/ViewArticle.aspx?d=Procedural+Breakth rough\&d_id=267\&i=June2011\&i_id=736\&a_id=17235. Accessed April 16, 2014.

49. Sakuragi T, Ohteki H. The utility of BiClamp $\left({ }^{\circledR}\right)$ for intraoperative air leakage control in video-assisted thoracic surgery for pulmonary lobectomy. Gen Thorac Cardiovasc Surg. 2012;60(11):781-783.

50. Hunt BM, Aye RW. Prolonged air leak after lung resection. Curr Respir Med Rev. 2012;8(4):280-284.

51. Bhatnagar NK, Berndt S. A solution to prolonged air leak after videoassisted thoracoscopic lobectomy. Ann Thorac Surg. 1995;59(1): 260-261.

52. Okereke I, Murthy SC, Alster JM, Blackstone EH, Rice TW. Characterization and importance of air leak after lobectomy. Ann Thorac Surg. 2005;79(4):1167-1173.

53. Aoki T, Ozeki Y, Watanabe M, Tanaka S. Cartilage folding method for main bronchial stapling. Ann Thorac Surg. 1998;65(6): 1800-1801.

54. Paul S, Altorki NK, Sheng S, et al. Thoracoscopic lobectomy is associated with lower morbidity than open lobectomy: a propensitymatched analysis from the STS database. J Thorac Cardiovasc Surg. 2010;139(2):366-378

55. Villamizar NR, Darrabie MD, Burfeind WR, et al. Thoracoscopic lobectomy is associated with lower morbidity compared with thoracotomy. J Thorac Cardiovasc Surg. 2009;138(2): 419-425.

56. Swanson SJ, Meyers BF, Gunnarsson CL, et al. Video-assisted thoracoscopic lobectomy is less costly and morbid than open lobectomy: a retrospective multiinstitutional database analysis. Ann Thorac Surg. 2012;93(4):1027-1032.

57. Park BJ. Is surgical morbidity decreased with minimally invasive lobectomy? Cancer J. 2011;17(1):18-22.

58. Gossot D, Merlusca G, Tudor A, Boudaya MS, Radu C, Magdeleinat P. Pitfalls related to the use of endostaplers during video-assisted thoracic surgery. Surg Endosc. 2009;23(1):189-192.

59. Gonzalez H, Avimukta K, Hall S. Data on file. Comparison of the number of malformed staple legs in $2-5 \mathrm{~mm}$ thick excised porcine stomach of the covidien Endo GIA Universal Roticulator 60 and the Ethicon Endo-Surgery Echelon FLEX 60 endoscopic linear surgical staplers. White paper. ETHICON ENDO-SURGERY, INC. Cincinnati, Ohio. 2010.

60. Akiyoshi T, Ueno M, Fukunaga Y, et al. Incidence of and risk factors for anastomotic leakage after laparoscopic anterior resection with intracorporeal rectal transection and double-stapling technique anastomosis for rectal cancer. Am J Surg. 2011;202(3):259-264. 
Medical Devices: Evidence and Research

Dovepress

\section{Publish your work in this journal}

Medical Devices: Evidence and Research is an international, peerreviewed, open access journal that focuses on the evidence, technology, research, and expert opinion supporting the use and application of medical devices in the diagnosis, treatment and management of clinical conditions and physiological processes. The identification of novel

devices and optimal use of existing devices which will lead to improved clinical outcomes and more effective patient management and safety is a key feature. The manuscript management system is completely online and includes a quick and fair peer-review system. Visit http://www. dovepress.com/testimonials.php to read real quotes from authors.

Submit your manuscript here: http://www.dovepress.com/medical-devices-evidence-and-research-journal 